\title{
Article \\ Study on the Performance of Synergistic Preparation of Sulphoaluminate Based Recycled Concrete by RP and RCA
}

\author{
Zhenwen $\mathrm{Hu}{ }^{1}$, Qiuyi $\mathrm{Li}^{1, *}$, Yuanxin Guo ${ }^{1, *}$, Xiangling Lin $^{2}$, Junzhe Liu ${ }^{1}$ and Shidong Zheng ${ }^{3}$ \\ 1 College of Architectural Engineering, Qingdao Agricultural University, Qingdao 266109, China; \\ 20192214693@stu.qau.edu.cn (Z.H.); liujunzhe@qau.edu.cn (J.L.) \\ 2 School of Civil Engineering, Qingdao University of Technology, Qingdao 266033, China; \\ 20202204006@stu.qau.edu.cn \\ 3 Shandong Junhong Environmental Technology Co., Ltd., Zibo 255000, China; zds@junhonghuanbao.com \\ * Correspondence: 201801001@qau.edu.cn (Q.L.); guoyuanxin@qau.edu.cn (Y.G.)
}

check for updates

Citation: Hu, Z.; Li, Q.; Guo, Y.; Lin, X.; Liu, J.; Zheng, S. Study on the Performance of Synergistic

Preparation of Sulphoaluminate Based Recycled Concrete by RP and RCA. Crystals 2021, 11, 748. https:// doi.org/10.3390/cryst11070748

Academic Editors: Yu Wang,

Amjad Albayati, Jian Geng and

Changquan Calvin Sun

Received: 4 June 2021

Accepted: 24 June 2021

Published: 26 June 2021

Publisher's Note: MDPI stays neutral with regard to jurisdictional claims in published maps and institutional affiliations.

Copyright: (c) 2021 by the authors. Licensee MDPI, Basel, Switzerland. This article is an open access article distributed under the terms and conditions of the Creative Commons Attribution (CC BY) license (https:// creativecommons.org/licenses/by/ $4.0 /)$.

\begin{abstract}
In this paper, the properties of sulphoaluminate based recycled concrete, with high workability and low and medium strength, prepared by recycled powder (RP), recycled coarse aggregate (RCA), and high belite sulphoaluminate cement (HBSAC), were systematically studied. Under the condition of a water binder ratio of 0.45 , sulphoaluminate based recycled concrete, with different mix proportions, was prepared by replacing sulphoaluminate cement with RP and natural coarse aggregate (NCA) with RCA. The workability, mechanical properties, durability, and hydration products of the prepared concrete were analyzed. The results showed that when RP and RCA were used together, the workability of recycled concrete could fully meet the pumping demand in actual construction. When the mass replacement rate of RP was less than $30 \%$ and that of RCA was less than $20 \%$, the strength of recycled concrete could completely reach the design strength grade, while those that did not reach the design strength grade could reach the next grade. The durability performance was also good.
\end{abstract}

Keywords: recycled powder (RP); recycled coarse aggregate (RCA); recycled concrete; mechanical properties; durability; hydration products

\section{Introduction}

Due to the continuous acceleration of China's urbanization process, the construction industry, as the backbone of the country's infrastructure construction, has an increasing demand for various building materials [1]. After decades of over-exploitation of natural sand and gravel, however, natural building material reserves are becoming limited and exhibit a depleting trend [2]. In addition, with the continuous demolition of waste buildings in the process of urbanization, the annual output of construction solid waste in China is increasing. However, compared with Europe, Japan and the United States, the utilization of construction solid waste in China is very low at less than 5\% of the annual output [3-7]. The contradiction between the shortage of building materials and the high output of construction solid waste caused by urbanization has brought great pressure and challenge to the sustainable development of China's resources and the environment [8-10]. Methods for transforming construction solid waste into a solution for the shortage of construction materials, thereby relieving the pressure of the sustainable development of resources and the environment, has become a hot research topic for scholars. At present, the main treatment method for construction solid waste in the world is through direct use as subgrade filler or crushed and screened as a recycled aggregate (recycled coarse and fine aggregate). From a cost perspective, the cost of direct landfill is lower than the cost of preparing recycled aggregate, but the cost of producing recycled coarse aggregate (RCA) is far lower than that of producing natural coarse aggregate (NCA) [11]. A research report pointed out that the long-term cost of producing 1t RCA was reduced by $40 \%$ compared with the production of 
1t NCA, and the environmental benefit was improved by $97 \%$ [12]. This not only solves, to a certain extent, the problem of building material shortages, but it also greatly eases the pressure of sustainable development of resources and the environment.

However, in the preparation of RCA, the microstructure is destroyed, resulting in a decline of the basic properties of the aggregate, and the application range is limited compared with NCA $[13,14]$. At present, application of RCA is used to partially replace NCA in order to reduce the pressure on resources and the environment $[15,16]$. Zand et al. replaced NCA in concrete filled steel tube (CFST) with a $0 \%, 30 \%, 50 \%$, and $70 \%$ mass substitution rate of RCA, and carried out a pure bending static load test on the prepared CFST specimens. The test results showed that the replacement of NCA by RCA reduced the flexural performance of CFST specimens, but the lower reduction could be controlled within $10 \%$, which had little effect on the strength of the specimens [17]. Bhat and others used the same method to crush different strength grades of building solid waste to prepare RCA, and replaced NCA with a 50\% and $100 \%$ mass substitution rate to prepare different strength grades of recycled concrete. The research results showed that the strength grade of recycled concrete was not affected by the strength grade of the building solid waste [18]. Attri et al. replaced NCA and river sand (RS) with RCA and recycled fine aggregate (RFA) in different proportions, and prepared paver blocks with RCA and RFA. Through the study on the mechanical properties and durability of paver blocks, it was found that when the mass substitution rate of RCA and RFA was less than $45 \%$ and $40 \%$, respectively, the properties of paver blocks were not significantly different from those of $100 \%$ NCA and RS [19]. Zhu used RCA to replace NCA with a $0 \%, 50 \%$, and $100 \%$ mass substitution rate to prepare recycled aggregate concrete beams, and carried out experimental research on the cracking, deformation, and deflection recovery value of the prepared concrete beams. It was found that the cracking and deformation of RCA concrete beams were greater than that of NCA concrete beams, and the cracking and deformation degree increased with the increase of RCA mass substitution rate. However, the deflection recovery value of the RCA concrete beam was larger than that of the NCA concrete beam [20]. In addition, in the process of preparing construction solid waste into recycled aggregate, part of the byproduct, recycled powder (RP), will inevitably be produced. RP is a powder with a particle size of less than $75 \mu \mathrm{m}$, and is mainly composed of gravel in aggregate and unhydrated cement particles in cement slurry. The relative research showed that RP also has certain hydration activity and can be used as a mineral admixture [21-26]. Deng et al. prepared submicron-RP (SRP) by wet grinding RP, and mixed SRP with a Portland cement system (PC), PC-granulated blast furnace lag (PC-GBFS), and a PC-fly ash (PC-FA) system at different mass substitution rates to investigate the compressive strength and hydration heat of different cementitious materials. The results showed that the compressive strength of the cementitious system with $6 \%$ SRP could be increased by $150 \%$ in $12 \mathrm{~h}$, and the heat of hydration could be increased by $100 \%$ in $12 \mathrm{~h}$ [27]. Ren et al. prepared an alkali activated slag concrete test block by replacing slag with a $20 \%, 40 \%$, and $60 \%$ mass replacement ratio of RP. Through the study of its strength, water absorption, and porosity, it was found that when the mass replacement ratio of RP was $20 \%$, the strength of the alkali activated slag concrete test block could be increased by about $13 \%$, and the water absorption and porosity also decreased to a certain extent [28].

All solid wastes are potential secondary resources. In addition to construction solid waste, which can be used to prepare recycled aggregate and admixture, ceramic waste and glass waste can also play the same role. Szelag et al. made recycled glass aggregate (RGA) by crushing waste automobile glass, and used RGA to replace RS with a 50\% and $100 \%$ mass substitution rate to prepare recycled concrete. The research found that the recycled concrete prepared by RGA had higher strength, impermeability, and lower water absorption [29]. Khan et al. prepared recycled glass powder (RGP) by grinding waste glass into powder, and used RGP to replace the cement with different mass substitution rates to prepare foam concrete. The test found that the compressive strength of the foam concrete could be increased under a mass substitution rate of RGP 20\% [30]. Siddique prepared fine 
bone china ceramic aggregate (FBA) by crushing waste ceramics, and prepared recycled concrete by replacing natural sand (NS) with FBA at a $20 \%, 40 \%, 60 \%, 80 \%$, and $100 \%$ mass substitution rate. Through the study of its strength and durability, it was found that using FBA to prepare recycled concrete could obtain higher strength and better durability [31]. $\mathrm{Xu}$ et al. prepared ceramic tile waste powder (CTWP) by grinding waste tiles into powder, and replaced ultra-high performance concrete (UHPC) with a 15-55\% mass substitution rate. Through strength, environmental impact, and cost analysis, it was found that the 28-day compressive strength and flexural strength of the concrete blocks containing CTWP were greater than $120 \mathrm{MPa}$ and $14 \mathrm{MPa}$, respectively. At a 55\% CTWP mass replacement rate, the $\mathrm{CO}_{2}$ emission and material cost of concrete blocks were reduced by $33.1 \%$ and $25.9 \%$, respectively [32].

Compared with Portland cement (OPC), sulphoaluminate cement (SAC) can significantly reduce the firing temperature of cement and the consumption of quicklime, which has considerable significance for energy saving and emissions reduction [33]. High belite sulphoaluminate cement (HBSAC) is a variant of SAC developed from SAC. It has the same green characteristics of low energy consumption and low emission as SAC, and its green degree is further improved compared with SAC because it uses a large amount of industrial waste slag and low-grade limestone to replace high-grade bauxite and limestone $[34,35]$.

In this paper, in order to further achieve energy conservation, emission reduction, and alleviate the pressure of the sustainable development of resources and the environment, RCA, RP, and HBSAC, three kinds of high green building materials, were combined together, with RCA and RP used to partially replace NCA and HBSAC, respectively. A sulphoaluminate based recycled concrete was prepared. With low and medium strength, green, high workability, rapid development of early strength, and easy construction, it is suitable for roads, ordinary pavements, and low-rise buildings. In addition, the workability, mechanical properties, and durability of recycled concrete were studied, and the micro morphology of hydration products of the RP cementitious material system was analyzed by scanning electron microscope (SEM).

\section{Materials and Methods}

\subsection{Test Materials}

Cement: high belite sulphoaluminate cement (HBSAC) (Hebei Tangshan Polar Bear Building Materials Co., Ltd.); and RP: the particle size was less than $75 \mu \mathrm{m}$. All its performance indicators met the Chinese industry standard JG/T 573-2020, "Recycled Micro Powder for Concrete and Mortar". The main components of the powder are shown in Table 1, and the XRD diffraction pattern of RP is shown in Figure 1. It can be seen from Figure 1 that the substances in the XRD pattern of RP are mainly active mineral components, such as $\mathrm{SiO}_{2}, \mathrm{CaO}, \mathrm{Al}_{2} \mathrm{O}_{3}$, and $\mathrm{Fe}_{2} \mathrm{O}_{3}$, with some $\mathrm{CaCO}_{3}$. $\mathrm{CaCO}_{3}$ is mainly formed by the carbonation of $\mathrm{Ca}(\mathrm{OH})_{2}$, the hydration product of cement, and $\mathrm{CO}_{2}$ in the air. Both active mineral components and $\mathrm{CaCO}_{3}$ can promote the hydration of cementitious materials and improve the strength of concrete blocks to a certain extent [36].

Table 1. Main components of powder.

\begin{tabular}{ccccccccc}
\hline Sample & $\mathrm{SiO}_{2} / \%$ & $\mathrm{CaO} / \%$ & $\mathrm{Al}_{2} \mathrm{O}_{3} / \%$ & $\mathrm{Fe}_{2} \mathrm{O}_{3} / \%$ & $\mathrm{MgO} / \%$ & $\mathrm{~K}_{2} \mathrm{O} / \%$ & $\mathrm{Na}_{2} \mathrm{O} / \%$ & $\mathrm{SO}_{3} / \%$ \\
\hline Cement & 18.62 & 44.52 & 14.30 & 1.81 & 3.76 & 0.01 & 0.17 & 15.64 \\
RP & 40.51 & 28.18 & 14.54 & 5.38 & 1.73 & 2.50 & 1.56 & 0.88 \\
\hline
\end{tabular}




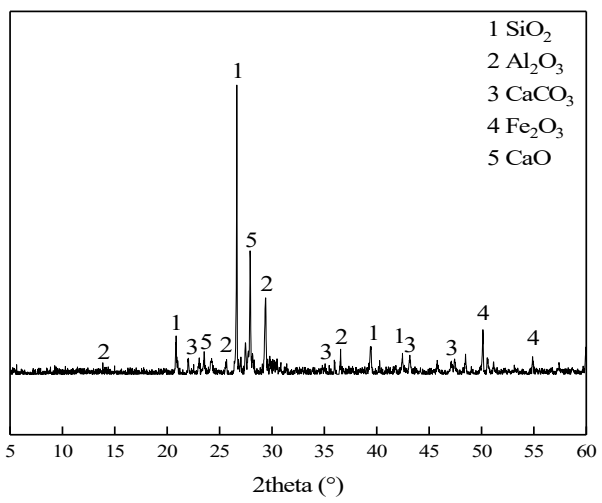

Figure 1. RP XRD diffraction pattern.

NCA: 4.75-20 mm continuous graded granite macadam, meeting the requirements of GB/T 14685-2011 "Pebble and Macadam for Building"; and RCA: the source of RCA was construction solid waste provided by the demolition site of a residential area in Qingdao. After simple crushing, the particle size range of RCA was $4.75-20 \mathrm{~mm}$, and all indexes met the requirements of GB/T 25177-2010, "Recycled Coarse Aggregate for Concrete". The main performance indexes of coarse aggregate are shown in Table 2, and the preparation process of RCA and RP are shown in Figure 2. The specific steps were carried out as follows: (1) sorting of the construction solid waste to remove glass, paper, plastic, and other debris, so only concrete was retained; (2) the concrete was crushed by jaw crusher. After crushing, it was sieved by shaker, and particles more than $20 \mathrm{~mm}$ in size were returned to jaw crusher for repeated crushing; and (3) after sieving by shaker, RCA particles and RP powders with particle sizes of $4.75-20 \mathrm{~mm}$ and less than $75 \mu \mathrm{m}$, respectively, were obtained.

Table 2. Main physical properties of coarse aggregate.

\begin{tabular}{ccccccc}
\hline Table 3. & $\begin{array}{c}\text { Powder } \\
\text { Content (\%) }\end{array}$ & $\begin{array}{c}\text { Water } \\
\text { Absorption (\%) }\end{array}$ & $\begin{array}{c}\text { Content of Needle } \\
\text { like Particles (\%) }\end{array}$ & $\begin{array}{c}\text { Crushing } \\
\text { Index (\%) }\end{array}$ & $\begin{array}{c}\text { Apparent Density } \\
\mathbf{( k g / \mathbf { m } ^ { 3 } )}\end{array}$ & $\begin{array}{c}\text { Porosity } \\
(\mathbf{\%})\end{array}$ \\
\hline RCA & 1.1 & 4.2 & 7.8 & 15.6 & 2395.2 & 48.9 \\
NCA & - & 0.9 & 3.5 & 10.2 & 2687.1 & 44.1 \\
\hline
\end{tabular}

Table 3. Main physical properties of fine aggregate.

\begin{tabular}{|c|c|c|c|c|c|}
\hline Type & $\begin{array}{c}\text { Powder Content } \\
(\%)\end{array}$ & $\begin{array}{l}\text { Fineness } \\
\text { Modulus }\end{array}$ & $\begin{array}{c}\text { Apparent Density } \\
\left(\mathrm{kg} / \mathrm{m}^{3}\right)\end{array}$ & $\begin{array}{l}\text { Bulk Density } \\
\left(\mathrm{kg} / \mathrm{m}^{3}\right)\end{array}$ & $\begin{array}{c}\text { Water Absorption } \\
(\%)\end{array}$ \\
\hline Machine-made sand & 0.8 & 2.7 & 2701.1 & 1489.2 & 0.67 \\
\hline
\end{tabular}

Water reducer: polycarboxylate superplasticizer; water reducing rate of $30 \%$.

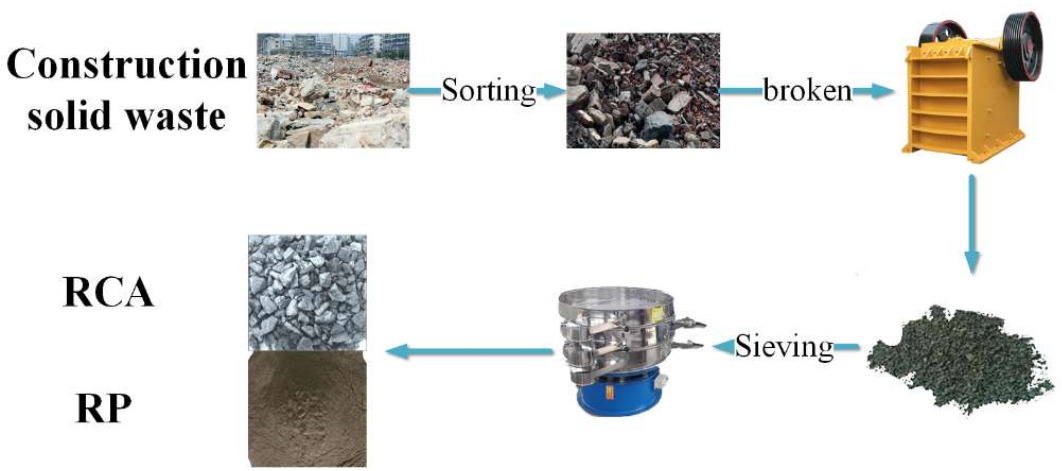

Figure 2. RCA and RP preparation process. 
Fine aggregate: machine-made sand, produced by a company in Qingdao, with all indexes meeting the requirements of GB/T 14684-2011, "Construction Sand". The fine aggregate physical properties are shown in Table 3.

\subsection{Concrete Mix Design}

In this experiment, the low and medium strength sulphoaluminate based recycled concrete, prepared by RP and RCA, was studied systematically. In the experiment, the target strength grade of the recycled concrete was C30, and the water binder ratio of the fixed recycled concrete was 0.45 in accordance with the mix proportion calculation in JGJ 55-2011, "Ordinary Concrete Mix Proportion Design Specification". At the same time, considering the high level of water absorption by RCA and RP, the workability of recycled concrete can decrease rapidly [37]. Moreover, RP has a large area, which can adsorb part of the water reducing agent and reduce its effect. In order to ensure that the recycled concrete had enough pumping performance in practical engineering, the superplasticizer, which accounts for $2 \%$ of the total mass of cementitious materials, was added. RP was used to partially replace cement with six gradients of $0 \%, 10 \%, 20 \%, 30 \%$, $40 \%$, and $50 \%$, while RCA was used to partially replace NCA with four gradients of $0 \%$, $10 \%, 20 \%$, and $30 \%$. Each group of tests was divided into six levels based on RP replacement rate, and comprehensive tests were used to study them. The mix proportion design of sulphoaluminate based recycled concrete is shown in Table 4.

Table 4. Mix design of sulphoaluminate based recycled concrete.

\begin{tabular}{|c|c|c|c|c|c|c|c|}
\hline \multirow{2}{*}{$\begin{array}{c}\text { Test } \\
\text { Number }\end{array}$} & \multirow{2}{*}{$\begin{array}{l}\text { Water Binder } \\
\text { Ratio }\end{array}$} & \multirow{2}{*}{$\begin{array}{l}\text { Water Reducer } \\
\quad\left(\mathrm{kg} / \mathrm{m}^{3}\right)\end{array}$} & \multirow{2}{*}{$\begin{array}{c}\text { Fine Aggregate } \\
\left(\mathrm{kg} / \mathrm{m}^{3}\right)\end{array}$} & \multicolumn{2}{|c|}{$\begin{array}{c}\text { Coarse Aggregate } \\
\left(\mathrm{kg} / \mathrm{m}^{3}\right)\end{array}$} & \multicolumn{2}{|c|}{$\begin{array}{c}\text { Cementitious Materials } \\
\left(\mathrm{kg} / \mathrm{m}^{3}\right)\end{array}$} \\
\hline & & & & RCA & NCA & $\mathbf{R P}$ & Cement \\
\hline$A-1$ & 0.45 & 5.6 & 608.0 & 0 & 1351.0 & 0 & 281.0 \\
\hline$A-2$ & 0.45 & 5.6 & 608.0 & 0 & 1351.0 & 28.1 & 252.9 \\
\hline$A-3$ & 0.45 & 5.6 & 608.0 & 0 & 1351.0 & 56.2 & 224.8 \\
\hline A-4 & 0.45 & 5.6 & 608.0 & 0 & 1351.0 & 84.3 & 196.7 \\
\hline$A-5$ & 0.45 & 5.6 & 608.0 & 0 & 1351.0 & 112.4 & 168.6 \\
\hline A-6 & 0.45 & 5.6 & 608.0 & 0 & 1351.0 & 140.5 & 140.5 \\
\hline B-1 & 0.45 & 5.6 & 608.0 & 135.1 & 1215.9 & 0 & 281.0 \\
\hline B-2 & 0.45 & 5.6 & 608.0 & 135.1 & 1215.9 & 28.1 & 252.9 \\
\hline B-3 & 0.45 & 5.6 & 608.0 & 135.1 & 1215.9 & 56.2 & 224.8 \\
\hline B-4 & 0.45 & 5.6 & 608.0 & 135.1 & 1215.9 & 84.3 & 196.7 \\
\hline B-5 & 0.45 & 5.6 & 608.0 & 135.1 & 1215.9 & 112.4 & 168.6 \\
\hline B-6 & 0.45 & 5.6 & 608.0 & 135.1 & 1215.9 & 140.5 & 140.5 \\
\hline$C-1$ & 0.45 & 5.6 & 608.0 & 270.2 & 1080.8 & 0 & 281.0 \\
\hline$C-2$ & 0.45 & 5.6 & 608.0 & 270.2 & 1080.8 & 28.1 & 252.9 \\
\hline$C-3$ & 0.45 & 5.6 & 608.0 & 270.2 & 1080.8 & 56.2 & 224.8 \\
\hline $\mathrm{C}-4$ & 0.45 & 5.6 & 608.0 & 270.2 & 1080.8 & 84.3 & 196.7 \\
\hline$C-5$ & 0.45 & 5.6 & 608.0 & 270.2 & 1080.8 & 112.4 & 168.6 \\
\hline$C-6$ & 0.45 & 5.6 & 608.0 & 270.2 & 1080.8 & 140.5 & 140.5 \\
\hline D-1 & 0.45 & 5.6 & 608.0 & 405.3 & 945.7 & 0 & 281.0 \\
\hline D-2 & 0.45 & 5.6 & 608.0 & 405.3 & 945.7 & 28.1 & 252.9 \\
\hline D-3 & 0.45 & 5.6 & 608.0 & 405.3 & 945.7 & 56.2 & 224.8 \\
\hline D-4 & 0.45 & 5.6 & 608.0 & 405.3 & 945.7 & 84.3 & 196.7 \\
\hline D-5 & 0.45 & 5.6 & 608.0 & 405.3 & 945.7 & 112.4 & 168.6 \\
\hline D-6 & 0.45 & 5.6 & 608.0 & 405.3 & 945.7 & 140.5 & 140.5 \\
\hline
\end{tabular}

\subsection{Concrete Preparation, Curing, and Performance Testing}

For each mix ratio, 24 pieces of $100 \times 100 \times 100 \mathrm{~mm}$ cube test blocks and 3 pieces of $100 \times 100 \times 400 \mathrm{~mm}$ rectangular parallelepiped test blocks were prepared. Among them, 12 cube test blocks were used for the mechanical performance test, 12 were used for the carbonization performance test, and 3 rectangular parallelepiped test blocks were used for the frost resistance test. During the preparation process, according to GB/T 50080- 
2016, "Standard for Test Methods for the Performance of Ordinary Concrete Mixtures", the slump of concrete at each mix ratio was tested. After preparation was completed in accordance with GB/T 50081-2019, "Mechanics of Ordinary Concrete Performance Test Method Standard", the concrete test block was subjected to standard curing. The mechanical performance test of the concrete test block, cured to the specified age according to GB/T 50082-2009, "Standard for Long-Term Performance and Durability Test Method of Ordinary Concrete", tested the durability of concrete test blocks cured to a specified age. The $\mathrm{RP}$ was mixed into HBSAC with a mass substitution rate of $0 \%, 10 \%, 20 \%$, and $30 \%$. Under the condition of a water-binder ratio of 0.45 , composite cementing material test blocks of $1 \times 1 \times 1 \mathrm{~cm}$ were prepared. After curing the test blocks for 28 days, drying and breaking them, a thin slice, with a length less than $2 \mathrm{~mm}$ and a thickness less than $0.5 \mathrm{~mm}$, was taken. The hydration products of cementitious materials were observed by high vacuum, GB-H mode, $2 \mathrm{KV}$ voltage, and $10 \mathrm{~mA}$ probe current scanning electron microscope.

\section{Results and Discussion}

\subsection{Concrete Workability}

After the concrete mixture was mixed, the slump test was conducted according to GB/T 50080-2016, "Standard for Test Methods for the Performance of Ordinary Concrete Mixtures". The test results are shown in Figure 3.

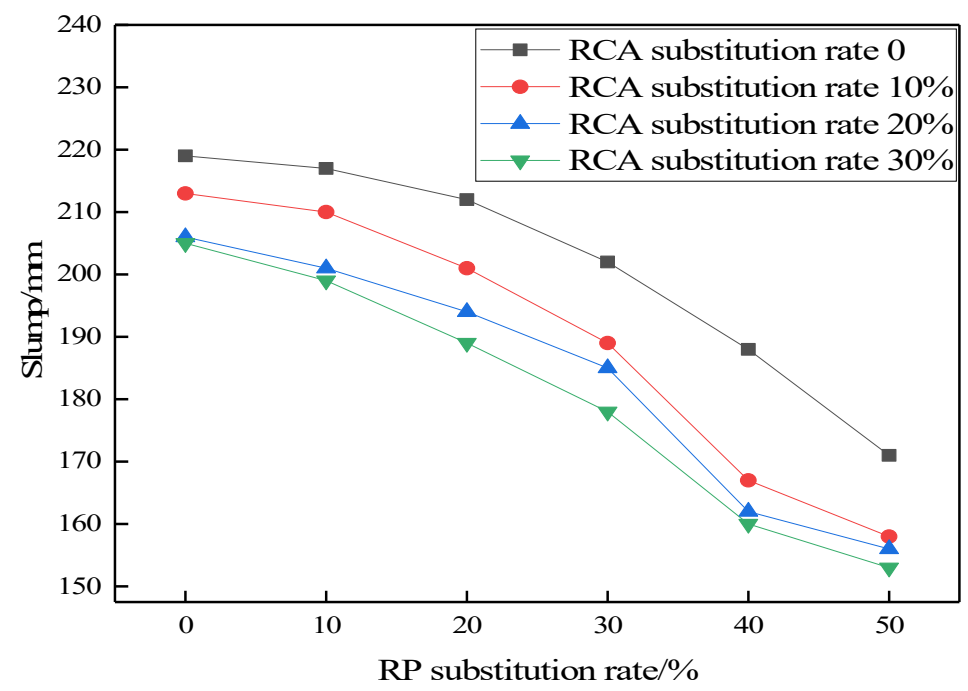

Figure 3. Slump of concrete in different test groups.

As can be seen in Figure 3 in the horizontal comparison, with the increasing replacement rate of RP, the workability of the concrete showed a downward trend. In the longitudinal comparison with the increase of RCA replacement rate, although the workability of concrete also showed a downward trend, the decline was far less than the impact of $\mathrm{RP}$ on the workability of recycled concrete. That is to say, the effect of RP on the workability of concrete was much greater than that of RCA.

In addition, when the replacement rate of RP was more than $10 \%$, the workability of the concrete in each experimental group decreased rapidly. This is because RP is not only poor in particle gradation, but also irregular in shape, which makes it unable to achieve a "ball effect" [38]. There are a large number of micro cracks in RP, which absorb a great deal of water and reduce the total amount of cement paste. With the increasing replacement rate of RP, the water absorption of RP also increased, which made the cement paste, which can wrap the aggregate and play the role of lubrication, decrease, resulting in the rapid decline of the workability of concrete [39]. Here, the effect of recycled materials on the concrete mixture was consistent with that found by Olofinade [39]. Although the fluidity of some test groups was as high as $200 \mathrm{~mm}$, there was no concrete segregation, which was mainly due to the fast setting speed and strong water retention of HBSAC. 


\subsection{Mechanical Properties of Concrete}

The mechanical properties of concrete blocks cured to the specified age were tested, and the strength change of concrete blocks is shown in Figure 4.

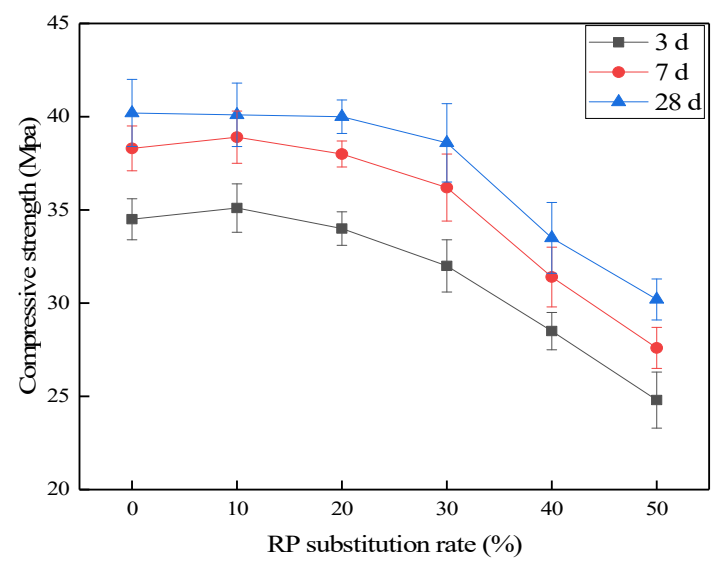

(a) A-RCA substitution rate $0 \%$

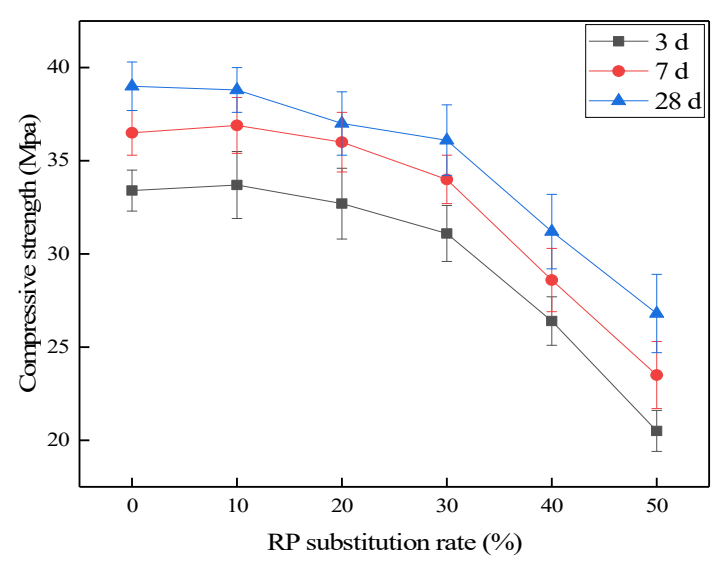

(c) C-RCA substitution rate $20 \%$

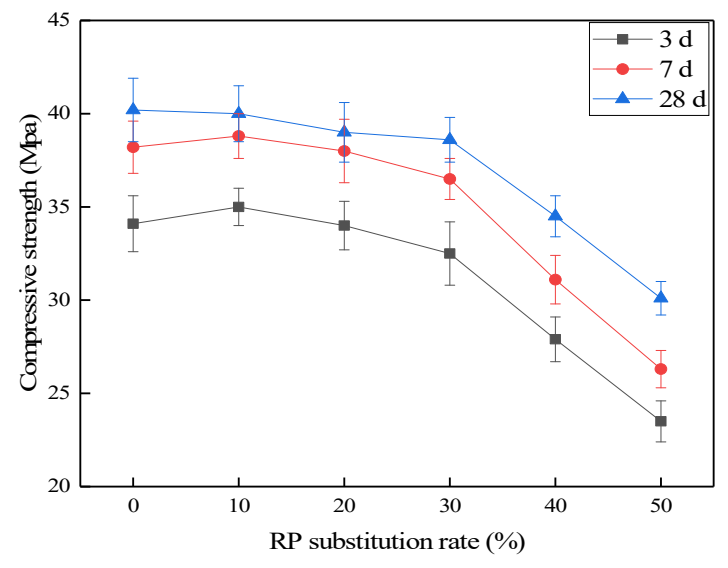

(b) B-RCA substitution rate $10 \%$

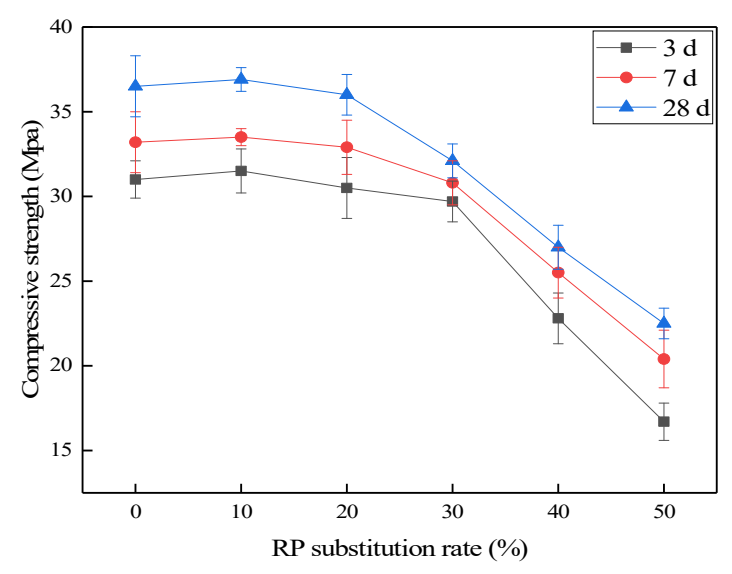

(d) D-RCA substitution rate $30 \%$

Figure 4. Strength of concrete blocks in different test groups.

As seen in Figure 4, the strengths of the concrete blocks in the different test groups did not differ much at 3 days, 7 days, and 28 days. In addition, when the RP replacement rate was $10 \%$, the strength of each group of concrete test block was similar to, or even slightly higher than, that of the pure cement test block. When the RP replacement rate was greater than $10 \%$, the strength of each group of concrete test blocks showed a linear downward trend. This is because the hydration process of HBSAC is very rapid compared with OPC, and a large number of hydration products can be generated in the early stage of hydration to provide strength. After RP was added to the cement with a substitution rate of $10 \%$, since RP also has hydration activity, the active substances in it underwent hydration, or a secondary hydration reaction, with cement hydration products forming gels to promote the increase in strength [40]. As the amount of $\mathrm{CH}$ consumed by the secondary hydration reaction increased, it also promoted the hydration reaction of cement, thereby further increasing the strength of the concrete test block. When the replacement rate of $\mathrm{RP}$ exceeded $10 \%$, especially when it reached more than $30 \%$, due to the increase in the replacement rate of RP, the cement paste was relatively reduced, resulting in a decrease in cement hydration products. This not only caused the secondary hydration reaction of the active substances in the RP to not fully generate gel to increase the strength of the concrete, 
but also caused the presence of a large number of loose and unhydrated RP particles in the concrete, resulting in a decrease in the compactness of the concrete and a rapid drop of the concrete test block intensity [41,42].

In addition, after comparing the concrete test blocks with the same RCA substitution rate in each test group, it was found that the strength of the concrete test block with an RCA substitution rate within $20 \%$ was similar in strength to the natural aggregate concrete test block. When the replacement rate of RCA exceeded $20 \%$, the strength of the concrete test block also dropped rapidly. This is due to the high water absorption rate of RCA, which will absorb a large amount of water in the cement paste, making the cement hydration incomplete and causing the strength of the concrete test block to decrease [37].

In conclusion, on the premise of ensuring the concrete strength, when RP and RCA are used together, the replacement rate of RP and RCA should not exceed $10 \%$ and $20 \%$, respectively. On this basis, not only is a good strength effect ensured, but it also greatly saves on the use cost. This is similar to the research conclusion of Aliabdo and Awoyera, wherein at a low substitution rate, recycled materials had no negative effect on the strength of recycled concrete, and even had a certain strengthening effect $[23,43]$.

\subsection{Carbonization Performance}

We put the standard curing 26-day cubic concrete test block in a $60^{\circ} \mathrm{C}$ drying box for $48 \mathrm{~h}$, and then placed it in a fast carbonization box with a temperature of $20^{\circ} \mathrm{C}, \mathrm{a} \mathrm{CO}$ concentration of $20 \%$, and a relative humidity of $70 \%$, after carbonization to the specified age. The measured carbonization depth is shown in Figure 5.

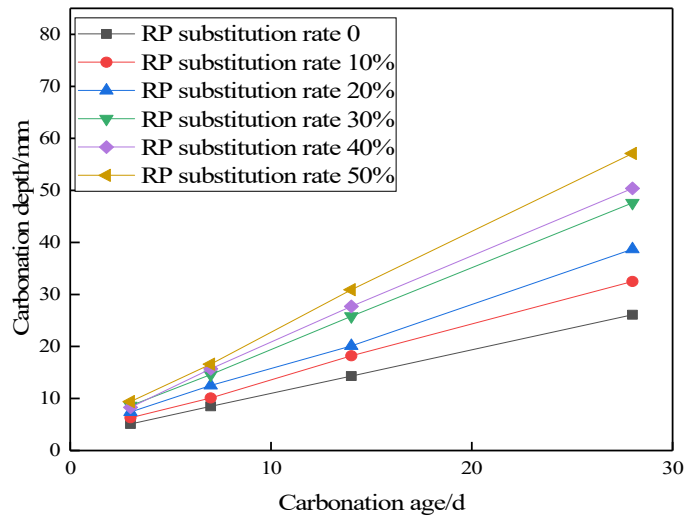

(a) A-RCA substitution rate $0 \%$

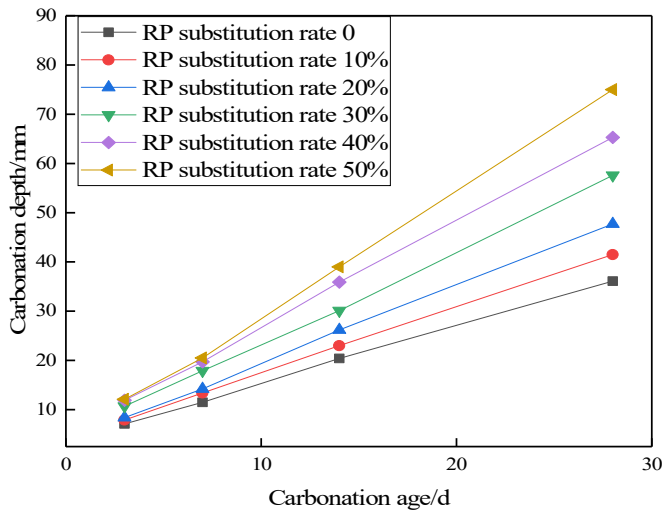

(c) C-RCA substitution rate $20 \%$

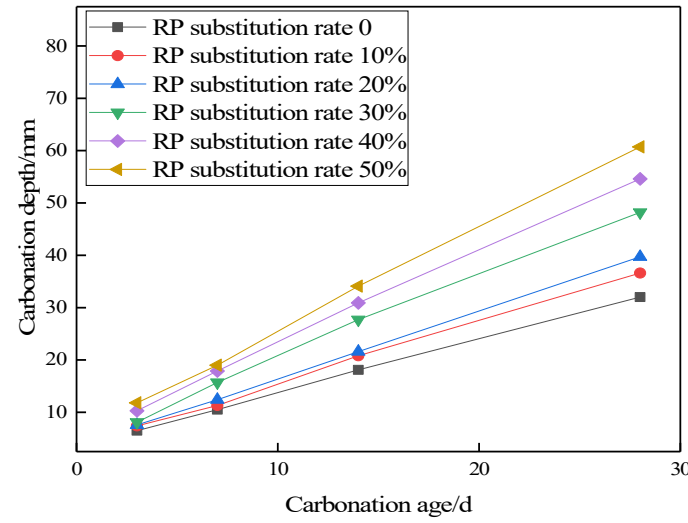

(b) B-RCA substitution rate $10 \%$

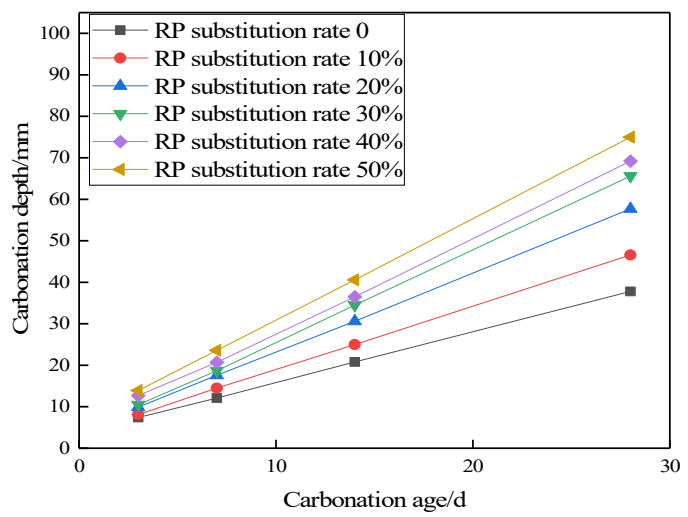

(d) D-RCA substitution rate $30 \%$

Figure 5. Carbonation depth of concrete blocks in different test groups. 
It can be seen from Figure 5 that, with the increase of the carbonization age, the carbonation depth of the concrete test blocks in each test group showed a continuous increasing trend. With the increase of the RP substitution rate, the carbonization depth also showed a continuous increasing trend. In addition, the carbonation depth in the group had a very large difference. With different RP substitution rates, the carbonization depth at 28 days differed by $37.2 \mathrm{~mm}$. Similarly, comparing the effect of RCA on the carbonization depth, it was found that with the increase of its substitution rate, although the concrete carbonization depth also showed an increasing trend, the maximum increase was only $17.9 \mathrm{~mm}$, which was smaller than the effect of RP on the carbonization depth of the concrete test blocks. It can be seen that the RP substitution rate had a greater negative impact on the carbonization depth of concrete. The main reason for this phenomenon is that, although RCA itself has some tiny cracks to provide channels for the diffusion of $\mathrm{CO}_{2}$ in concrete blocks, due to its low substitution rate, the total amount of channels is small, and the impact on the carbonation depth of concrete is small [38]. However, RP not only has micro-cracks to provide channels for $\mathrm{CO}_{2}$ diffusion, but also affects the process of cement hydration. During the secondary hydration process, a large amount of $\mathrm{CH}$ was consumed, which greatly reduced the ability of the concrete test block to resist carbonization [24].

In summary, adding RP and RCA to concrete had a negative impact on the anticarbonization ability of recycled concrete, but the negative effect of RP was greater than that of RCA on the anti-carbonization ability of concrete test blocks.

\subsection{Frost Resistance}

The rectangular concrete test block, which was cured for 24 days, was fully soaked for 4 days and then placed in the rapid freeze-thaw box for a frost resistance test. The mass loss rate and relative dynamic elastic modulus of the concrete test block were taken as the evaluation criteria. The test results are shown in Figures 4 and 5.

It can be seen from Figures 6 and 7 that the influence of RP was also greater than the influence of RCA on the frost resistance of concrete, and the relative dynamic elastic modulus of the concrete specimens of each test group showed an accelerated decline. When the content of RP was less than 30\%, the mass loss rate of concrete blocks in each group first increased and then decreased with the increase of the freeze-thaw cycles. When the replacement rate was more than $30 \%$, the mass loss rate of the concrete blocks in each experimental group increased linearly. The main reason for this phenomenon was that both RCA and RP had a negative impact on the frost resistance of the concrete test block, causing the dynamic elastic modulus to continue to decline. However, when the replacement rate of RP was less than $30 \%$, the pressure generated by free water freezing in concrete at the early stage of the freeze-thaw cycle expanded the internal pores of the concrete, but it did not reach the failure state. The quality of the water absorbed by the concrete itself was greater than the quality of spalling loss caused by the freeze-thaw cycle. In the later period of the freeze-thaw cycle, due to the increase of free water inside the concrete, the internal pressure generated after the free water froze caused a large amount of destructive spalling on the concrete test block. The quality of this part of the spalling was much greater than the quality of the absorbed water, thus increasing the quality loss. However, in the test group with an RP substitution rate of more than $30 \%$, because the porosity of the concrete test block was too large and the structure too loose, a large amount of destructive spalling occurred in the early stage of the freeze-thaw cycle, causing the mass loss rate to increase rapidly. The above results are similar to those of Lei [44].

In addition, when the RP content exceeded $20 \%$, to meet the requirements of the national standard, the maximum number of freeze-thaw cycles for the concrete test blocks of each test group was only 25 times. The main reason for the inflection points of freezethaw resistance at $20 \% \mathrm{RP}$ replacement rate was that, when the replacement rate of RP was higher than $20 \%$, the amount of hydration product $\mathrm{CH}$ produced by cement hydration was reduced, so that the secondary reaction of RP was inhibited and the compaction degree of the concrete test block was greatly reduced [24]. There were a lot of micro cracks in RP 
without secondary reaction. The free water in these cracks further damaged the aggregate and slurry under the freeze-thaw cycle. In summary, when the replacement rate of RP was greater than $20 \%$, it had a large negative impact on the frost resistance of the concrete.

\subsection{Microscopic Analysis of Hydration Products}

In order to support the above analysis, the hydration products of cementitious materials mixed with RP were observed. The hydration products were observed by SEM under different magnification. The SEM images are shown in Figure 8.

According to Figure 8, no RP particles were found in the SEM images with pure cement and an RP substitution rate of $10 \%$, and the hydration products were mainly gelatin and dense structure, which could provide higher strength. In the image of an RP substitution rate of $20 \%$ and $30 \%$, unhydrated RP particles were found, and the amount of gel generation was less and the structure was loose. Although unhydrated RP particles were found in the images with both a $20 \%$ and $30 \%$ RP substitution rate, the unhydrated $\mathrm{RP}$ particles in the images with a $30 \% \mathrm{RP}$ substitution rate were much higher, the structure was more loose, and the void was larger. This effectively proves the effectiveness of the previous analysis.

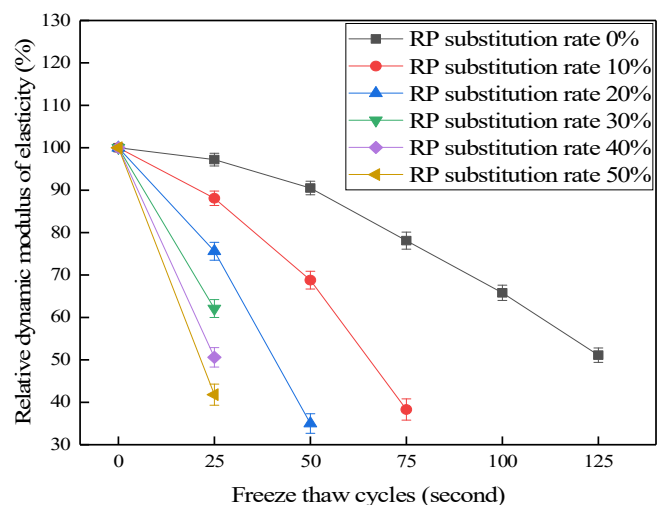

(a) A-RCA substitution rate $0 \%$

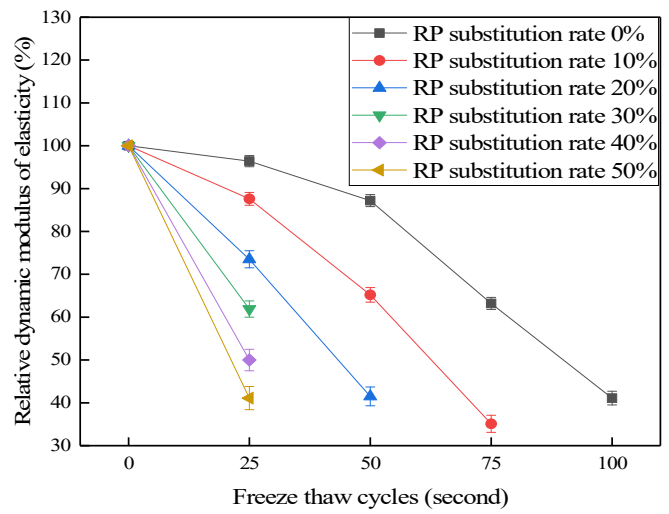

(c) C-RCA substitution rate $20 \%$

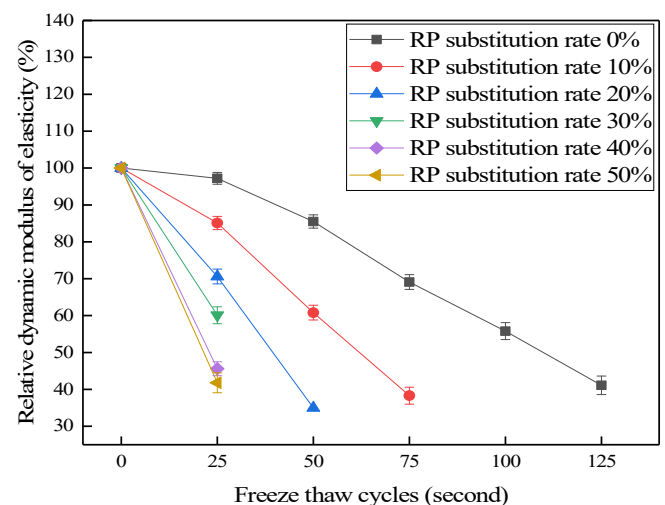

(b) B-RCA substitution rate $10 \%$

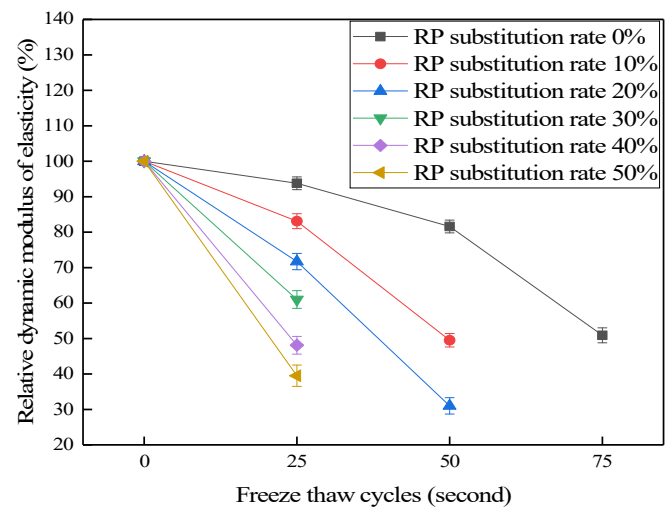

(d) D-RCA substitution rate $30 \%$

Figure 6. Change of relative dynamic elastic modulus of concrete blocks in different test groups. 


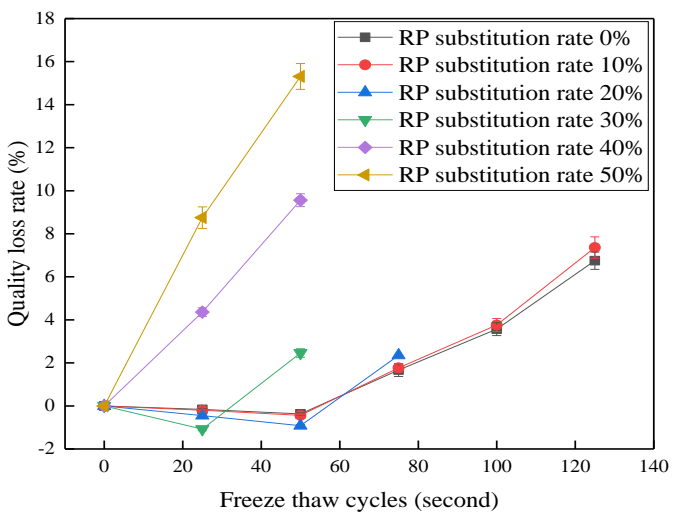

(a) A-RCA substitution rate $0 \%$

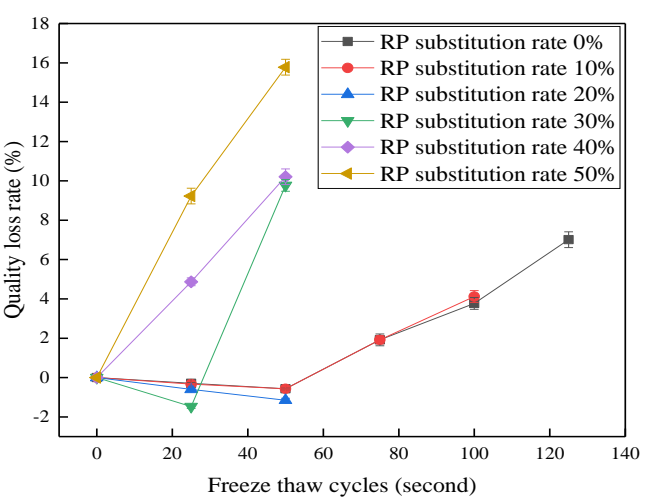

(c) C-RCA substitution rate $20 \%$

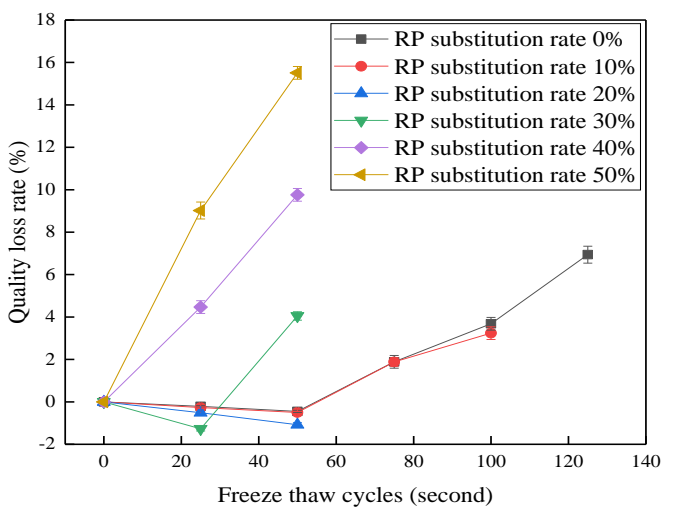

(b) B-RCA substitution rate 10\%

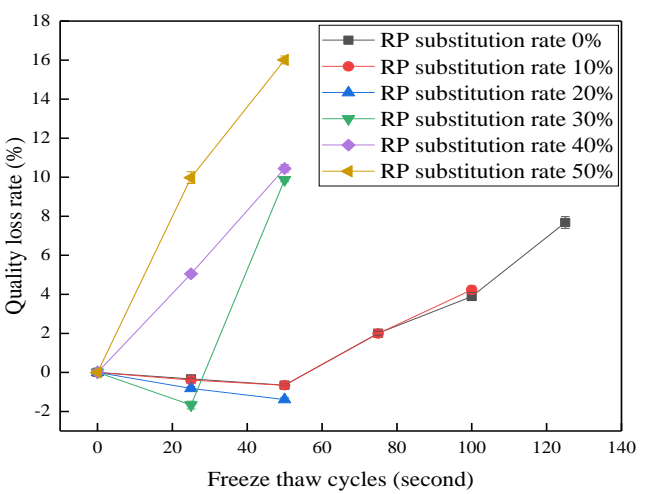

(d) D-RCA substitution rate $30 \%$

Figure 7. Change of mass loss rate of concrete blocks in different test groups.

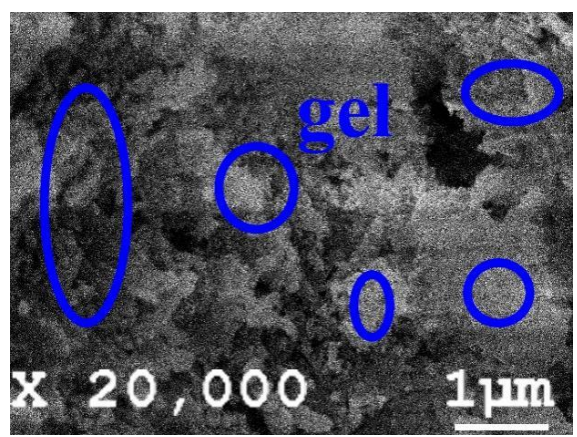

(a) Pure cement

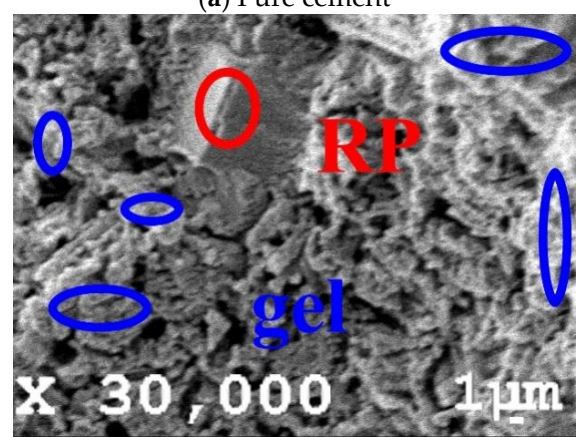

(c) RP substitution rate $20 \%$

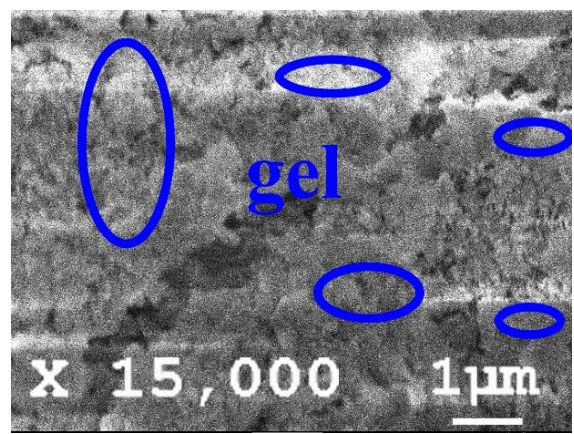

(b) RP substitution rate $10 \%$

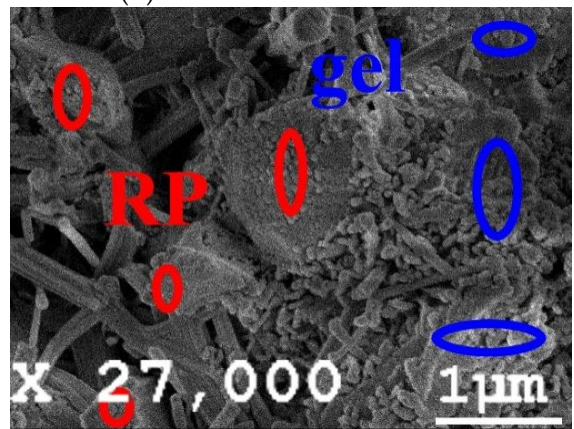

(d) RP substitution rate $30 \%$

Figure 8. Microstructure of hydration products of cementitious materials with different RP substitution rates. 


\section{Conclusions}

In this study, three kinds of high green building materials RCA, RP, and HBSAC were combined to prepare a sulphoaluminate based recycled concrete. Through systematic analysis of the working performance, mechanical properties, durability of recycled concrete, and hydration products of the cementitious material system, the following conclusions were drawn:

(1) Under the premise of a fixed water binder ratio of 0.45 , the replacement rate of RCA for NCA was less than $30 \%$, and the replacement rate of RP for HBSAC was less than $50 \%$. The slump of all concrete mixtures reached more than $150 \mathrm{~mm}$, and there was no concrete segregation phenomenon, which could fully meet the demand of pumping concrete in the actual construction process;

(2) Under the condition of fixed water binder ratio of 0.45 , the 28 -day strength grade of recycled concrete blocks in all test groups could reach $\mathrm{C} 20$. When the replacement rate of RP was less than $30 \%$ and RCA was less than $20 \%$, the 28 -day strength grade of all recycled concrete blocks could reach C30; and the strength of all groups of concrete could reach more than $80 \%$ of the 28 -day age strength when it was cured to the 3 day age. On the basis of greatly reducing the cost of concrete preparation, the construction efficiency was greatly improved;

(3) Under the condition of fixed water binder ratio of 0.45 , when RP and RCA were used to prepare sulphoaluminate based recycled concrete, both had a negative impact on the durability of the concrete, but the negative impact of RP on the durability of recycled concrete was greater than that of RCA, especially when the content of RP was more than $20 \%$, the frost resistance of recycled concrete declined sharply;

(4) In this experiment, the sulphoaluminate based recycled concrete prepared by RCA and RP fully met the requirements for roads, ordinary pavements, and low-rise buildings. However, due to its low design strength and high water binder ratio, the highest strength grade of the recycled concrete only reached C30, and its durability was also low under a high replacement rate of RCA and RP. In the follow-up study, the design strength of recycled concrete can be improved, reducing its water binder ratio, and the influence of RCA and RP on the performance of high-strength sulphoaluminate based recycled concrete can be explored.

Author Contributions: Data curation, Y.G. and S.Z.; formal analysis, Z.H. and X.L.; investigation, Q.L. and J.L.; methodology, Z.H. and Y.G.; resources, X.L. and Y.G.; software, X.L.; writing-original draft, Z.H.; writing - review and editing, Q.L. All authors have read and agreed to the published version of the manuscript.

Funding: This research was funded by the National Natural Science Foundation of China (grant numbers 51878366, 51808310,51978353 and 52078261), the Natural Science Foundation of Shandong Province, China, (grant numbers ZR2019PEE007 and ZR2020ME036), and the Qingdao Science and Technology Demonstration and Guidance project (20-3-4-10-nsh).

Data Availability Statement: Since the experiment was completed with the support of Qingdao Agricultural University, the data used to support the results of this study are available from the responsible person and the author upon request.

Conflicts of Interest: The authors declare no conflict of interest regarding the publication of this paper.

\section{References}

1. Zhang, C.; Hu, M.; Dong, L.; Xiang, P.; Zhang, Q.; Wu, J.; Li, B.; Shi, S. Co-benefits of urban concrete recycling on the mitigation of greenhouse gas emissions and land use change: A case in Chongqing metropolis, China. J. Clean. Prod. 2018, 201, 481-498. [CrossRef]

2. Xiao, J.; Li, W.; Fan, Y.; Huang, X. An overview of study on recycled aggregate concrete in China (1996-2011). Constr. Build. Mater. 2012, 31, 364-383. [CrossRef]

3. Tang, Q.; Ma, Z.; Wu, H.; Wang, W. The utilization of eco-friendly recycled powder from concrete and brick waste in new concrete: A critical review. Cem. Concr. Compos. 2020, 114, 103807. [CrossRef] 
4. Yue, G.; Ma, Z.; Liu, M.; Liang, C.; Ba, G. Damage behavior of the multiple ITZs in recycled aggregate concrete subjected to aggressive ion environment. Constr. Build. Mater. 2020, 245, 118419. [CrossRef]

5. Kapoor, K.; Singh, S.; Singh, B.; Singh, P. Effect of recycled aggregates on fresh and hardened properties of self compacting concrete. Mater. Today Proc. 2020, 32, 600-607. [CrossRef]

6. Lu, W. Big data analytics to identify illegal construction waste dumping: A Hong Kong study. Resour. Conserv. Recycl. 2019, 141, 264-272. [CrossRef]

7. Guerra, B.C.; Bakchan, A.; Leite, F.; Faust, K.M. BIM-based automated construction waste estimation algorithms: The case of concrete and drywall waste streams. Waste Manag. 2019, 87, 825-832. [CrossRef]

8. Wu, H.; Zuo, J.; Zillante, G.; Wang, J.; Yuan, H. Status quo and future directions of construction and demolition waste research: A critical review. J. Clean. Prod. 2019, 240, 118163. [CrossRef]

9. Seror, N.; Portnov, B.A. Estimating the effectiveness of different environmental law enforcement policies on illegal C\&D waste dumping in Israel. Waste Manag. 2020, 102, 241-248. [CrossRef] [PubMed]

10. Xiao, J.; Ma, Z.; Ding, T. Reclamation chain of waste concrete: A case study of Shanghai. Waste Manag. 2016, 48, 334-343. [CrossRef] [PubMed]

11. Tam, V.W. Economic comparison of concrete recycling: A case study approach. Resour. Conserv. Recycl. 2008, 52, 821-828. [CrossRef]

12. Ohemeng, E.A.; Ekolu, S.O. Comparative analysis on costs and benefits of producing natural and recycled concrete aggregates: A South African case study. Case Stud. Constr. Mater. 2020, 13, e00450. [CrossRef]

13. Rao, M.C.; Bhattacharyya, S.K.; Barai, S.V. Influence of field recycled coarse aggregate on properties of concrete. Mater. Struct. 2010, 44, 205-220. [CrossRef]

14. Wang, R.; Yu, N.; Li, Y. Methods for improving the microstructure of recycled concrete aggregate: A review. Constr. Build. Mater. 2020, 242, 118164. [CrossRef]

15. Mistri, A.; Bhattacharyya, S.K.; Dhami, N.K.; Mukherjee, A.; Barai, S.V. A review on different treatment methods for enhancing the properties of recycled aggregates for sustainable construction materials. Constr. Build. Mater. 2020, 233, 117894. [CrossRef]

16. Yehia, S.; Helal, K.; Abusharkh, A.; Zaher, A.; Istaitiyeh, H. Strength and Durability Evaluation of Recycled Aggregate Concrete. Int. J. Concr. Struct. Mater. 2015, 9, 219-239. [CrossRef]

17. Al Zand, A.W.; Hosseinpour, E.; Badaruzzaman, W.H.W.; Ali, M.M.; Yaseen, Z.M.; Hanoon, A.N. Performance of the novel C-purlin tubular beams filled with recycled-lightweight concrete strengthened with CFRP sheet. J. Build. Eng. 2021, $43,102532$. [CrossRef]

18. Bhat, J.A. Effect of strength of parent concrete on the mechanical properties of recycled aggregate concrete. Mater. Today Proc. 2021, 42, 1462-1469. [CrossRef]

19. Attri, G.K.; Gupta, R.; Shrivastava, S. Impact of recycled concrete aggregate on mechanical and durability properties of concrete paver blocks. Mater. Today Proc. 2021, 42, 975-981. [CrossRef]

20. Zhu, C.; Liu, C.; Bai, G.; Fan, J. Study on long-term performance and flexural stiffness of recycled aggregate concrete beams. Constr. Build. Mater. 2020, 262, 120503. [CrossRef]

21. Zhao, Z.; Rémond, S.; Damidot, D.; Xu, W. Influence of fine recycled concrete aggregates on the properties of mortars. Constr. Build. Mater. 2015, 81, 179-186. [CrossRef]

22. Duan, Z.; Singh, A.; Xiao, J.; Hou, S. Combined use of recycled powder and recycled coarse aggregate derived from construction and demolition waste in self-compacting concrete. Constr. Build. Mater. 2020, 254, 119323. [CrossRef]

23. Xiao, J.; Ma, Z.; Sui, T.; Nezhad, A.A.; Duan, Z. Mechanical properties of concrete mixed with recycled powder produced from construction and demolition waste. J. Clean. Prod. 2018, 188, 720-731. [CrossRef]

24. Gupta, T.; Siddique, S.; Sharma, R.K.; Chaudhary, S. Behaviour of waste rubber powder and hybrid rubber concrete in aggressive environment. Constr. Build. Mater. 2019, 217, 283-291. [CrossRef]

25. Gebremariam, A.T.; Vahidi, A.; Di Maio, F.; Moreno-Juez, J.; Vegas-Ramiro, I.; Łagosz, A.; Mróz, R.; Rem, P. Comprehensive study on the most sustainable concrete design made of recycled concrete, glass and mineral wool from C\&D wastes. Constr. Build. Mater. 2021, 273, 121697. [CrossRef]

26. Huo, W.; Zhu, Z.; Chen, W.; Zhang, J.; Kang, Z.; Pu, S.; Wan, Y. Effect of synthesis parameters on the development of unconfined compressive strength of recycled waste concrete powder-based geopolymers. Constr. Build. Mater. 2021, 292, 123264. [CrossRef]

27. Deng, X.; Guo, H.; Tan, H.; He, X.; Zheng, Z.; Su, Y.; Yang, J. An accelerator prepared from waste concrete recycled powder and its effect on hydration of cement-based materials. Constr. Build. Mater. 2021, 296, 123767. [CrossRef]

28. Ren, P.; Li, B.; Yu, J.-G.; Ling, T.-C. Utilization of recycled concrete fines and powders to produce alkali-activated slag concrete blocks. J. Clean. Prod. 2020, 267, 122115. [CrossRef]

29. Szelag, M.; Zegardło, B.; Andrzejuk, W. The Use of Fragmented, Worn-Out Car Side Windows as an Aggregate for Cementitious Composites. Materials 2019, 12, 1467. [CrossRef]

30. Khan, Q.S.; Sheikh, M.N.; McCarthy, T.J.; Robati, M.; Allen, M. Experimental investigation on foam concrete without and with recycled glass powder: A sustainable solution for future construction. Constr. Build. Mater. 2019, 201, 369-379. [CrossRef]

31. Siddique, S.; Chaudhary, S.; Shrivastava, S.; Gupta, T. Sustainable utilisation of ceramic waste in concrete: Exposure to adverse conditions. J. Clean. Prod. 2019, 210, 246-255. [CrossRef] 
32. Xu, K.; Huang, W.; Zhang, L.; Fu, S.; Chen, M.; Ding, S.; Han, B. Mechanical properties of low-carbon ultrahigh-performance concrete with ceramic tile waste powder. Constr. Build. Mater. 2021, 287, 123036. [CrossRef]

33. Gao, Y.; Li, Z.; Zhang, J.; Zhang, Q.; Wang, Y. Synergistic use of industrial solid wastes to prepare belite-rich sulphoaluminate cement and its feasibility use in repairing materials. Constr. Build. Mater. 2020, 264, 120201. [CrossRef]

34. Lu, Z.; Hou, D.; Ma, H.; Fan, T.; Li, Z. Effects of graphene oxide on the properties and microstructures of the magnesium potassium phosphate cement paste. Constr. Build. Mater. 2016, 119, 107-112. [CrossRef]

35. Liu, C.; Luo, J.; Li, Q.; Gao, S.; Su, D.; Zhang, J.; Chen, S. Calcination of green high-belite sulphoaluminate cement (GHSC) and performance optimizations of GHSC-based foamed concrete. Mater. Des. 2019, 182, 107986. [CrossRef]

36. Zhang, J.; Zhou, Z.H.; Cheng, X. Formation Kinetics of Regenerated Cement Clinker Calcined by Using Wasted Recycling Concrete Powders as Raw Meals. Adv. Mater. Res. 2014, 1073-1076, 1309-1312. [CrossRef]

37. Miličević, I.; Bjegović, D.; Siddique, R. Experimental research of concrete floor blocks with crushed bricks and tiles aggregate. Constr. Build. Mater. 2015, 94, 775-783. [CrossRef]

38. Hou, Y.F.; Chen, J.L. Performance of powders in recycled aggregate. J. Beijing Univ. Civ. Eng. Archit. 2010, 26, 8-11. [CrossRef]

39. Olofinnade, O.; Ogara, J. Workability, strength, and microstructure of high strength sustainable concrete incorporating recycled clay brick aggregate and calcined clay. Clean. Eng. Technol. 2021, 3, 100123. [CrossRef]

40. Pedro, D.; de Brito, J.; Evangelista, L. Evaluation of high-performance concrete with recycled aggregates: Use of densified silica fume as cement replacement. Constr. Build. Mater. 2017, 147, 803-814. [CrossRef]

41. Wang, H.; Xia, Y. Influence of recycled fine powder on shrinkage cracking of concrete. Ind. Constr. 2016, 46, 122-125. [CrossRef]

42. Xu, C.; Zhao, T.; Yu, F. Application of waste clay brick powder in grouting material. Concrete 2019, 6, 71-75. (in Chinese) [CrossRef]

43. Awoyera, P.O.; Okoro, U.C. Filler-Ability of Highly Active Metakaolin for Improving Morphology and Strength Characteristics of Recycled Aggregate Concrete. Silicon 2018, 11, 1971-1978. [CrossRef]

44. Lei, B.; Li, W.; Tang, Z.; Tam, V.W.; Sun, Z. Durability of recycled aggregate concrete under coupling mechanical loading and freeze-thaw cycle in salt-solution. Constr. Build. Mater. 2018, 163, 840-849. [CrossRef] 